\title{
TRABALHO, MEIO AMBIENTE E EDUCAÇÃO: APONTAMENTOS À EDUCAÇÃO AMBIENTAL A PARTIR DA FILOSOFIA DA PRÁXIS
}

\section{LABOR, ENVIRONMENT AND EDUCATION: NOTES FOR ENVIRONMENTAL EDUCATION IN THE PHILOSOPHY OF PRACTICE}

\section{Alexandre Maia do Bomfim}

\section{RESUMO}

Este estudo quer contribuir com um determinado desenvolvimento teóricometodológico que tem se pautado a pensar a "Questão Ambiental" a partir do materialismo dialético. Aqui, também há a intenção de resgatar o Trabalho como categoria chave e lançar novas reflexões para a Educação Ambiental EA. A partir de autores identificados com o marxismo, este estudo propôs-se partir da seguinte questão: que tipo de EA é possível construir tendo como pano de fundo a crítica ao sistema capitalista? Este trabalho chegou às inferências: de que o marxismo pode oferecer, à reflexão da EA, a possibilidade de resgatar um humanismo, sendo mantida a perspectiva de classe; de que uma das tarefas da EA pode ser desvelar o discurso ideológico sobre "Desenvolvimento Sustentável"; de que há necessidade permanente de problematização da própria EA. E, por último, em contrapartida, de que a própria "Questão Ambiental" imprime dialeticamente ao marxismo novos desafios teórico-metodológicos.

PALAVRAS-CHAVES: Educação Ambiental - Marxismo - Trabalho e Educação.

\section{ABSTRACT}

This study wants to contribute a certain theoretical and methodological development has been guided to think of "Environmental Issues" with the dialectical materialism. Here, there is also the intention to redeem the human labor as a key category and initiate new ideas for Environmental Education - 
EE. From the authors identified with Marxism, this study proposed to analyze the following question: what kind of EE can be built with the backdrop of criticism of the capitalist system? This work led to the inference: that Marxism can offer, the reflection of the EA, the possibility of rescuing a humanism, which kept the class perspective, that the tasks of the EE can be unveiling the ideological discourse on "Sustainable Development" ; that there is continued need for discussion of the EE itself. And, finally, that the very "Environmental Issues" prints dialectical Marxism new theoretical and methodological.

KEYWORDS: Environmental Education - Marxism - Labor and Education. 


\section{TRABALHO, MEIO AMBIENTE E EDUCAÇÃO: APONTAMENTOS À EDUCAÇÃO AMBIENTAL A PARTIR DA FILOSOFIA DA PRÁXIS}

\section{APRESENTAÇÃO: NÓS E ELES, TRABALHADORES...}

[Montaigne] perguntou [aos índios brasileiros] o que haviam achado de Paris, e eles responderam que haviam achado muito estranho que na cidade existissem, lado a lado, palácios de pessoas muito ricas e tantos mendigos, tão pobres, morando nas ruas. E indagaram: por que os mendigos não queimam os palácios e matam os ricos? (cf. KONDER, 2006)

Antes de tudo vale a pena resgatar um episódio que acredito teve uma ligação com a escolha deste estudo. Há alguns anos participei de um Curso de Formação de Formadores da CUT, organizado pela Escola Sete de Outubro da Central Única dos Trabalhadores. Nesse curso, alguns acontecimentos despertaram-me mais interesse e surpresa do que seu próprio conteúdo. $\mathrm{Na}$ busca de relacionamento interpessoal, as questões mais comuns que se ouvia, logo após a pergunta pelo nome, eram: "qual o seu partido político?", “qual a sua tendência?". Nós, os que vínhamos da universidade (apesar de minha origem suburbana e de filho de metalúrgico), com o tempo também não fomos poupados, sobretudo quando nossas preferências não ficavam tão claras. Uma questão nos era colocada constantemente, direta ou indiretamente: "Do que vocês estão falando?", o que me pareceu uma forma de desqualificar nosso discurso. No meio do curso, isso foi evidenciado e conseguimos empreender um debate a esse respeito; acredito que, a partir desse momento, conseguimos até reverter um pouco o quadro, pois nos deixaram novamente falar. De qualquer forma, isso já havia causado um grande efeito na minha percepção e reflexão sobre o significado da relação entre trabalhadores, educação, trabalho e política... Por que tanta desconfiança dos trabalhadores em relação à Universidade, em relação à Academia?

O presente estudo quer contribuir com um determinado desenvolvimento teórico-metodológico que tem se pautado a pensar a 
"Questão Ambiental" a partir do materialismo dialético (cf. CHESNAY; SERFATI, 2003, DELUIZ; NOVICKI, 2004, LOWI, 2005, LOUREIRO, 2007, entre outros). Aqui, a intenção é resgatar o Trabalho como categoria chave e lançar novas reflexões à Educação Ambiental - EA. A proposta é retomar, à luz de uma ciência encarnada e que não signifique panfletária, uma direção diferente do atual produtivismo acadêmico. E quiçá, devolver aos trabalhadores essa reflexão, especialmente aos educadores ambientais, de forma que a perspectiva de classe não seja suprimida por uma perspectiva apolítica de EA.

\title{
2 CIÊNCIA, POLÍTICA, PRÁXIS: O RESGATE do TRABALHO COMO CATEGORIA SOCIOLÓGICA CENTRAL
}

\begin{abstract}
A dialética não é o método da redução: é o método da reprodução espiritual e intelectual da realidade é o método do desenvolvimento e da explicitação dos fenômenos culturais partindo da atividade prática objetiva do homem histórico. (KOSIK)
\end{abstract}

Marx em sua XI Tese contra o materialismo de Feuerbach, diz: Os filósofos se limitaram a interpretar o mundo de diferentes maneiras; mas o que importa é transformá-lo (MARX; ENGELS, 1977, p. 128). Ainda que a idéia principal seja potencializar a luta entre Capital e Trabalho, não se pode alcançá-la sem a necessária busca pelo conhecimento. Aqui, transformar está ligado à necessidade de conhecer:

\footnotetext{
Somos seres de carne e osso, seres vivos, engajados na aventura de viver. Existimos agindo, tomando decisões, fazendo escolhas, tomando iniciativas, trabalhando, utilizando na nossa atividade o imprescindível (embora precário) conhecimento disponível. É na prática, na realização dos nossos projetos, que checamos a justeza de nossos pensamentos e a verdade dos conhecimentos em que nos apoiamos (KONDER, 2002, p. 261).
}

Marx era um militante político, mas poucas seriam as pessoas a desconsiderá-lo como sendo um estudioso profundo e com rigor. A obra "O Capital", por exemplo, é resultado construído em mais de 20 anos de seus estudos. Enfim, qual a melhor relação ou síntese entre transformar e 
conhecer? Ainda que não possa desenvolver aqui a resposta, pode-se dizer que ela não virá "dizendo a mesma coisa do que já foi dito".

A reflexão teórico-metodológica é uma das tarefas científicas mais difíceis. Num tempo de "desconstruções" teóricas, de concepções pósmodernas, de novas formas de imperialismo... Não há estudo que possa escapar de novas questões. Não obstante, não se deve embarcar em novas teorizações abruptamente, sem reflexão, muitas vezes por modismo. A questão é saber se as proposições teóricas do materialismo dialético, por exemplo, continuam valendo. Reconhecer a crise não significa endossar as teses de seu fim e da necessidade de substituí-lo por outros paradigmas (...) (FRIGOTTO 1998, p. 26).

A crítica dos pós-modernos ao projeto da Modernidade deve ser considerada em muitos aspectos, contudo, não a ponto de aceitarmos as teses de "fim da história", "esgotamento da razão", relativismo absoluto, etc. Não obstante, há pontos que a filosofia da práxis - termo lapidado por Gramsci, que Konder (1992) aponta ser a designação adequada para o materialismo iniciado por Marx - precisa investir mais (ou mesmo reconsiderar), como, por exemplo: a mediação da linguagem na relação sujeito/objeto; a relação homem/natureza, no sentido da preservação ecológica (escopo deste trabalho); o tipo especial de olhar sobre as sociedades "não-capitalistas"; etc.

Para a Filosofia da Práxis o conhecimento não acontece definitivamente, pode até haver a preocupação com a questão do conhecimento ser ou não falível, ser ou não superficial, mas não da "verdade" existir ou não plenamente. O conhecimento que se obtém é para a realização da própria verdade. A grande diferença é que para o materialismo isto não é apenas uma questão de retórica, mas é processado pela própria história.

Por esta razão a história humana pode ser o processo da verdade e a história da verdade. A destruição da pseudoconcreticidade significa que a verdade não é inatingível, nem alcançável de uma vez para sempre, mas que ela se faz; logo, se desenvolve e se realiza (KOSIK, 1986, p. 23). 
Então, um dos primeiros movimentos que pode fazer quanto à questão do conhecimento é perguntar: se as coisas, que assim se apresentam, não poderiam estar de outra forma?

A idéia de práxis em si mesma pressupõe avaliação: somos resultado das relações concretas e do que "entendemos" destas relações. A partir deste ponto de vista seria inapropriado dizer se há ou não práxis, pois sempre haveria. E mais, a práxis que se apresenta, nunca será definitiva, não se apresentará do mesmo jeito a todo tempo. A relação teoria e prática estará sempre sendo refeita, independente de/para quem seja, de ser boa ou não Nos Manuscritos econômicos e filosóficos, Marx desenvolveu sua concepção do homem como um criativo e livre ser da práxis de forma tanto "positiva" como "negativa", essa última por meio da crítica da auto-realização humana. (BOTTOMORE, 2001, p.293) - de ser dialógica ou de ser simplesmente razoável. Não obstante, a idéia de práxis pode assumir - dentro de uma perspectiva marxista - somente o seu aspecto positivo:

Neste sentido, entendemos a "práxis" como aquilo que incessantemente pretende fazer a relação Teoria e Prática, que não somente aceita este movimento, como o estimula e que busca o novo. Enquanto, a "alienação" como aquilo que reifica uma determinada relação entre Teoria e Prática, ou melhor, estimula sua cisão a pólos estanques e estáticos.

\footnotetext{
"Práxis" opunha-se, portanto, não à poiesis ou à Theoria, mas a práxis "má", alienada (...). Aos invés de falar de boa e má práxis, estes autores [filósofos marxistas iugoslavos da década 50 e 60] preferiram falar de práxis autêntica e práxis alienada, ou de forma mais simples, de práxis e alienação. (BOTTOMORE, 2001, p. 295).
}

E vai ser no Trabalho que a práxis vai se realizar. Certamente que nem toda atividade prática é práxis, pois a práxis seria a atividade de quem faz escolhas conscientes e para isso necessita de teoria (KONDER, 2001, p. 15). Destarte, é no Trabalho que o homem faz a si mesmo. Neste planeta não há uma só pessoa que não viva do trabalho, se não for de seu próprio, vive do trabalho alheio. Foi e é por meio do trabalho, da relação com a natureza e com os demais, que o homem se fez e continua a se fazer. Ainda que aceitemos a máxima bíblica de que "Nem só de pão vive o homem", há de se complementar 
de que não existe ser humano que viva sem pão. E de que, a percepção da injustiça se dá pela desigualdade econômica, assim como as mazelas da degradação ambiental são concretas e a principal tarefa do Estado na sociedade capitalista é exatamente a proteção da propriedade privada. Numa só palavra: materialidade! Pensar a degradação ambiental nessa direção acaba por se fazer imprescindível.

O que há, de fato, em Marx é o entendimento dos processos econômicos como ontologicamente determinantes da vida social, posto que aí se definem as formas de produção, relações de propriedade em torno daquilo que é gerado para garantir a sobrevivência da espécie e os meios instituídos para a sociedade assegurar sua reprodução e existência. (LOUREIRO, 2007, p. 53)

Mais expressivo materialmente do que a extinção da própria espécie humana, só mesmo a destruição do planeta! Na verdade, é este "modo de produção" experimentado pela sociedade capitalista que vem exaurindo a Terra. Ainda que o termo "modo de produção" pareça démodé para muitos pensadores, é sob essa "forma de manutenção e desenvolvimento da vida" que construímos esta sociedade consumidora, poluidora, desigual e bélica. A "Questão Ambiental" revigora a teoria marxista, mas vai ser essa teoria quem vai redirecionar o problema. Porque só a crítica mais implacável ao capitalismo tem condição de realmente apontar os seus limites, suas contradições. E com certeza as críticas mais agudas não sairão das teorias e pensadores alinhados ao sistema social vigente.

Pensar a "Questão Ambiental" na perspectiva do Trabalho, quer dizer, dos homens e mulheres trabalhadores, especialmente dos incluídos precariamente e dos excluídos, parece ser o mais avançado e lugar de construção de uma esperança concreta.

\section{UM PROJETO INTEGRADO - TRABALHO, MEIO AMBIENTE E EDUCAÇÃO}

Antes de qualquer desenvolvimento, é importante esclarecer que este estudo se insere efetivamente entre duas "áreas": "Trabalho e Educação" e "Educação e Meio Ambiente" (ou "Educação Ambiental", se preferir). Faz-se importante esse esclarecimento, porque embora sejam temáticas convergentes 
- precisamente o que queremos defender -, o percurso teórico que essas áreas tiveram no interior da área de Educação não foi imediatamente próximas. E se dermos à "Trabalho e Educação" a identificação com o marxismo (cf. BOMFIM, 2006), acabaremos por perguntar, como Löwy (2005):

Em que medida o pensamento de Marx e Engels é compatível com a ecologia moderna? Podemos conceber uma leitura ecológica de Marx? Quais são as aquisições do marxismo indispensáveis à constituição de um ecossocialismo à altura dos desafios de século $\mathrm{XXI}$ ? (p. 19)

Destarte, não sendo evidente a proximidade entre os "verdes" (ecologistas) e "vermelhos" (marxistas) (cf. LÖWY, 2005), também não será evidente a análise que procura compreender a tal "questão ambiental" sob a perspectiva do "Trabalho". Não obstante, é exatamente isso que nos propomos aqui. "Trabalho" aqui entendido dentro da teoria marxista, como uma categoria social chave (justamente o contrário do que apresentou OFFE, 1989) e na sua dupla mediação. Na "mediação de primeira ordem", o trabalho é a própria relação do homem com a natureza, indispensável à constituição desse próprio homem, que ao transformar a natureza acaba por se transformar também. E na "mediação de segunda ordem", o Trabalho na relação subordinada ao Capital é responsável pela produção das mercadorias, assim se posiciona como o próprio lugar de exploração do trabalhador.

Atualmente as questões sobre meio ambiente alcançaram um vulto expressivo, diante da constatação de que: o aquecimento global já trouxe mudanças irreversíveis à natureza, está em aceleração e o homem é o maior responsável. Essas foram algumas das conclusões a que chegaram os cientistas ligados ao IPCC - Painel Intergovernamental sobre Mudança do Clima (Intergovernmental Panel on Climate Change), apresentadas em fevereiro de 2007 (IPCC, 2007). O modelo de desenvolvimento da sociedade capitalista está mais uma vez sendo questionado, agora mais evidentemente à questão do meio ambiente, mas, como sempre o foi em relação às questões da desigualdade social, exploração do trabalho, à participação do poder, à exclusão, etc. Em relação a essas variadas formas de exploração, vale trazer Marx e Engels em uma de suas obras clássica, o Manifesto Comunista, para 
recuperar à memória: "Depois de sofrer a exploração do fabricante e de receber seu salário em dinheiro, o operário torna-se presa de outros membros da burguesia, do proprietário, do varejista, do usurário, etc" (MARX; ENGELS, 1968, p. 31).

O capitalismo como também indicara Marx no Manifesto ampliou as cidades submetendo o campo, concentrou o Capital, trouxe a subjugação das forças da natureza (ibid., 28), alienou do trabalhador a riqueza que ele verdadeiramente produziu/produz, etc.

Frigotto (1998) lembra que até um liberal como Noberto Bobbio propôs a necessidade de se reler Marx (Invito a rileggere Marx!). O que não dá para atribuir imediatamente ao Marx de 1848, iluminista, seria a percepção de que a pauta sobre a "questão do meio ambiente" viria tão rápida, ou melhor, viria antes mesmo do esgarçamento previsto entre Capital e Trabalho (MARX; ENGELS, 1968). O capitalismo passou e ainda passa por vários momentos de crise, cria subterfúgios que em longo prazo aprofundarão a crise, mas pode ser que esteja forjando antecipadamente não somente as armas que the darão morte (ibid) quanto classe, mas também morte ao planeta e ou à boa parte de seus demais viventes (CHESNAIS; SERFATI 2003).

A "questão do meio ambiente" vem se incorporar à pauta de luta dos trabalhadores, não deve se restringir apenas aos ambientalistas ou ecologistas, pois revela como o atual modelo de desenvolvimento é insustentável e que há necessidade de mudança de rota.

A proposta é problematizar também tudo isso dentro da Educação, a partir da seguinte questão: Que tipo de Educação Ambiental é possível construir tendo como pano de fundo a crítica implacável ao sistema capitalista? 


\section{MARXISTAS E AMBIENTALISTAS: POR UM REFERENCIAL TEÓRICO COMUM}

"O custo, em termos de depredação do mundo físico, desse estilo de vida, é de tal forma elevado que toda tentativa de generalizá-lo levaria inexoravelmente ao colapso de toda uma civilização, pondo em risco as possibilidades de sobrevivência da espécie humana." (Celso Furtado em 1974)

Duas obras de autores reconhecidamente marxistas foram escolhidas para esta parte do artigo: o livro Ecologia e Socialismo de (LÖWY, 2005) e o artigo "Ecologia" e condições físicas de reprodução social: alguns fios condutores marxistas (CHESNAIS; SERFATI, 2003). Com eles tecemos considerações, que julgamos importantes, para a reflexão da "Questão Ambiental" pela filosofia da práxis, para a Educação Ambiental.

Em seu livro, Löwy resgata, em principalmente Marx e em Engels, reflexões e passagens que valem de crítica comum ao Capitalismo tanto para os socialistas quanto para os ecologistas. E Löwy faz isso com muito cuidado, para não forçar por demais uma visão de que em Marx e Engels havia plena "consciência ecológica". Não obstante, vê na crítica de Marx ao desenvolvimento capitalista como o ponto principal a ser incorporado à luta dos verdes.

Percebe-se a intenção de mostrar que as reticências que possuem os ecologistas em relação aos marxistas não são producentes, já que se restringem em apontar em Marx o seu viés antropocêntrico.

Löwy, evitando uma postura dogmática, não destitui de Marx suas características iluministas e, de alguma forma, reconhece os limites do seu entendimento, mas aproveita para rebater alguns pontos fechados de alguns ecologistas a respeito, que: na luta pela preservação da natureza acabam esquecendo do homem, conseqüentemente da situação dos trabalhadores, das populações marginalizadas, etc. Ou seja, Löwy exalta o humanismo de Marx, como parte integrante e indispensável na luta pela natureza. O livro traz várias partes dos clássicos, de Marx e Engels, pertinentes à questão do meio ambiente: 
Nós não devemos nos vangloriar demais das nossas vitórias humanas sobre a natureza. Para cada uma destas vitórias, a natureza se vinga de nós. É verdade que cada vitória nos dá, em primeira instância, os resultados esperados, mas em segunda e terceira instâncias ela tem efeitos diferentes, inesperados, que muito freqüentemente anulam o primeiro. (ENGELS apud LÖWI, 2005, p. 22)

Essa passagem mostra o alcance que teve o marxismo já no século XIX, o Engels de 1876 ainda se mostra atual para entender o tipo de desenvolvimento impetrado pelo capitalismo. O que Löwy procura mostrar é que a exploração e o aviltamento dos trabalhadores são postos em paralelo, como resultado da mesma lógica predatória (ibid., p. 30).

Não obstante, da mesma forma que Löwy teceu uma crítica aos verdes não-humanistas, há também uma para os marxistas: o calcanhar-deaquiles do raciocínio de Marx e Engels era (...) uma concepção acrítica das forças produtivas capitalistas (...) como se elas fossem "neutras" (ibid., p. 39). Löwy mostra a existência de uma leitura dentro do marxismo que, de algum modo, preserva a estrutura produtiva do capitalismo, pois não vê nela o mal, mas somente em quem a conduz. Porém, tal leitura enviesada incorre num erro. Löwy argumenta que a tecnologia, obviamente não-neutra, já prescreve em si um direcionamento, possivelmente já degradador. Em alguns casos, precisam as máquinas ser concretamente "quebradas", pois não há o que salvar, por exemplo, nas indústrias bélicas ou naquelas evidentemente poluidoras. Löwy não propõe um novo movimento luddista, mas percebe que não vai ser simplesmente mudando o comando que a estrutura vai mudar.

Os trabalhadores não podem [apenas] apoderar-se do aparelho de Estado capitalista e pô-lo em funcionamento em benefício próprio. Devem "quebrá-lo" e substituí-lo por outro, de natureza totalmente distinta, uma forma não-estatal e democrática de poder político. (ibid., p. 55)

Qual caminho efetivamente deve ser seguido? O que fica como 'ponto em comum' para os verdes e os vermelhos? Inicialmente, é o ponto de partida a crítica voraz ao modelo de desenvolvimento capitalista. Não obstante, para Löwy o caminho a ser seguido não pode ser o da - que ele chama "escola otimista" e nem o da "escola pessimista". A "escola otimista" é aquela 
que ainda vê a possibilidade de desenvolvimento ilimitado, desde que se opte pelas forças produtivas adequadas; enquanto que a "escola pessimista" seria abrir mão drasticamente do desenvolvimento, diminuir 0 crescimento demográfico e o nível de vida das populações (ibid., p. 56). Para o autor, o caminho é qualificar o desenvolvimento, abandonar definitivamente alguns elementos depredadores inatos, como o da indústria de armas, etc. e ir à direção do que ele chama de necessidades autênticas: água, comida, roupas, moradia (ibid.). Uma ética ecossocialista (ibid.) precisa ser adquirida urgentemente (no presente!) e precisa ser mais do que garantir às gerações futuras um planeta habitável - idéia implícita ao "desenvolvimento sustentável". Se não começarmos agora, não há futuro.

Apesar dessa grande contribuição de Löwy, uma contribuição que possui uma crítica em volume máximo à Questão ambiental é feita na obra de Chesnay e Serfati (cf. CHESNAY; SERFATI, 2002). Embora, de algum modo, Chesnay e Serfati aceitem a proximidade da luta política entre "verdes" e "vermelhos" porque teriam como pano de fundo a crítica ao Capitalismo, se distanciam um pouco de Löwy na qualificação dessa luta. Chesnay e Serfati não vêem que a destruição da natureza seja uma contradição ao "Sistema do Capital" (cf. MÉSZÁROS, 2002), como vê Löwy.

Löwy havia apontado que a destruição da natureza seria também ameaça ao Capitalismo, pois estaria exaurindo a natureza da mesma forma que faz com o trabalhador, pois para Löwy a destruição da natureza seria a $2^{\underline{a}}$ contradição do Capital. Já Chesnay e Serfati (ibid.) divergem dessa visão, mostram em seu estudo que o Capital em seu movimento de depredação da natureza na verdade não é ameaçado, nem mesmo num momento posterior, como seria na sua relação com o Trabalho. O Capital necessita da exploração do Trabalho para valorizar-se, essa é sua única contradição. A escassez da natureza não é uma ameaça ao Sistema Capital, porque será essa mesma escassez que proporcionará bons novos negócios. Quanto mais a natureza se exaurir, mas se vislumbra a possibilidade de mercantilizar a água, 0 ar, a beleza, o que restar do verde, dos animais, etc. O Sistema do Capital é capaz de destruir primeiro a natureza, o ser humano, do que a si mesmo. Com Chesnay e Serfati, pode-se inferir que a luta dos vermelhos e verdes está 
estritamente condicionada à transformação integral do Sistema do Capital. Não há caminho intermediário - e parafraseando Rosa de Luxemburgo (2002) - 0 que há: Socialismo ou Colapso Planetário!

A maior contribuição de Löwy foi mostrar que não é suficiente assumir espaços de produção e de poder dentro do capitalismo se for mantida a sua lógica. Por exemplo, não há nada de libertador se os trabalhadores assumirem uma fábrica de armas ou mesmo de agrotóxicos pesados, elas por si mesmas se propõem a atividades nefastas para uma sociedade nãoexcludente. O viés - possivelmente equivocado - de Löwy é pretender que a percepção dos defensores do Capitalismo, diante da $2^{\underline{a}}$ contradição (a destruição da natureza) pudesse dar sentido a um novo tipo de desenvolvimento.

O combate para salvar o meio-ambiente, que é necessariamente o combate por uma mudança de civilização, é um imperativo humanista, que diz respeito não apenas a esta ou àquela classe social, mas ao conjunto dos indivíduos. (LÖWY, 2005, p. 73)

Essa passagem de Löwy é realmente temerária. A lógica de que vivemos num mesmo planeta e de que o mal-estar sentido por todos pode engendrar uma mudança de rota é substrato da utopia de Löwy. Ainda que Löwy tenha ciência de que quem sofre primeiro e mais com a degradação da natureza são os pobres, parece nutrir a esperança de que quando os ricos forem atingidos algo possa mudar. Em Chesnais e Serfati não há espaço para esse tipo de esperança porque, mantida a perspectiva de classe, sabe-se que o capital é plenamente capaz de transferir o peso das degradações para os países e classes mais fracas (CHESNAIS; SERFATI, 2003, p. 43). A relação rico e pobre, mais do que uma relação econômica é antes de tudo política, ligase às questões de poder e manutenção da ordem. A única possibilidade do "mal-estar ecológico" atingir substancialmente os ricos é se algo acontecer repentinamente e de forma globalizante, de outra forma, haverá tempo para transferir as mazelas aos mais pobres. Outro ponto a acrescentar: não é simplesmente a conscientização de que o planeta pode ser destruído - pelo menos este habitável à espécie humana - suficiente para mudança de rota. $\mathrm{O}$ quanto é possível atingir com uma conscientização ecológica, já que há inúmeros conflitos de interesse? 
E do outro lado, opondo-se à consciência, há a alienação. A nossa sociedade humana vem há muito tempo mantendo distorções abissais, poucos com muito e muitos com pouco, noutros tempos foram legitimadas pela religião, mas, agora no capitalismo se mantêm num Estado laico. Como?

Os mecanismos para a manutenção da alienação, considerando a relação Capital e Trabalho, foram denunciadas há tempos pelo marxismo, mas valem até hoje: dos (mecanismos) presentes no interior da produção, como 0 da fragmentação do trabalho, da mais-valia; dos no âmbito educacional, como a imposição da cultura hegemônica; aos que perpassam pelo uso concreto da força... E certamente mecanismos que valem também para entender a "questão ambiental".

\title{
5 CONCLUSÃO: O QUE FICA PARA A EDUCAÇÃO AMBIENTAL?
}

\author{
Este é tempo partido, \\ Tempo de homens partidos (...) \\ Os homens pedem carne. Fogo. \\ Sapatos. \\ As leis não bastam. Os lírios não \\ nascem da lei. Meu nome é tumulto, e \\ escreve-se na pedra. \\ (Carlos Drummond de Andrade)
}

Enfim, precisamente a partir do título deste último item, considerando a questão posta pelos trabalhadores (pelo Trabalho), a práxis como princípio e meta, o marxismo como referencial: o que fica para Educação Ambiental - EA?

O primeiro ponto que o marxismo pode oferecer à reflexão da EA é a possibilidade de resgatar o humanismo, de garantir um aporte teórico que privilegia o homem em sua integralidade e não corresponde somente à fração dominante de uma determinada sociedade humana. E nessa perspectiva, constituir uma crítica que possa hierarquizar a responsabilidade concreta da degradação ambiental.

Outro ponto é ter como base uma pesquisa científica que tem a práxis materialista como horizonte, o que significa investigar para além do aparente, com a intenção de destruir a pseudoconcreticidade, de denunciar as 
relações de fetiche em nossa sociedade. Algo parecido com o que descreve Kosik, em sua crítica à economia clássica:

\begin{abstract}
A economia clássica não descreve o mundo humano no seu aspecto alienado e não mostra como as relações histórico-sociais dos homens são mascaradas pela relação e pelo movimento das coisas; (...) porque não conhece nenhum outro mundo humano, a não ser 0 mundo reificado. (KOSIK, 1995, p. 98)
\end{abstract}

A EA precisa ressignificar suas tarefas, apontar não somente as mazelas engendradas pelo sistema do capital, mas principalmente denunciar as suas formas de camuflá-las, as falsas ou paliativas políticas públicas ou mesmo as inúmeras propostas de ação em nome de um "desenvolvimento sustentável".

Um terceiro ponto de contribuição do marxismo à $E A$ é o de impetrar-lhe uma reflexão desconfiada, porque conforme o conteúdo de classe ao qual estiver exposta, ela pode ser uma educação para a alienação ou uma educação para a emancipação (MARX; ENGELS apud RODRIGUES, 2003, p. 49). Para EA é necessário, antes de tudo, partir de uma das máximas que Marx cunhou nas "Teses sobre Feuebach" de que o próprio educador deve ser educado (MARX; ENGELS, 1977, p.12). Ou seja, é necessário que, no mínimo, - Educador Ambiental tenha como princípio a necessidade permanente de revisar a sua prática, em relação ao seu conteúdo utilizado, às metodologias, etc. E mais ainda - provavelmente o mais importante - a contribuição da EA não está a ela própria circunscrita, porque embora a conscientização seja passo indispensável não é suficiente. É necessário atingir a luta política, imprescindível à mudança do atual modelo de desenvolvimento e à esperança. Uma EA crítica é aquela que percebe a inevitabilidade do confronto político, porque assim como acontece com a relação capital e trabalho, a questão ambiental liga-se a conflitos de interesses, característica de uma sociedade desigual.

E por fim, vale refletir também o quanto a chamada "questão ambiental" revigora o próprio marxismo (a contrapartida). Ser marxista não é subserviência ao pensamento de Marx, na verdade, como lembra Konder (2006), "marxista" era um termo pejorativo utilizado por adversários de Marx em 
sua época. Não obstante, um educador que se considere crítico certamente precisará garantir elementos da Filosofia da Práxis, entre vários pontos, significa assumir a história como processo, como movimento e resultado do conflito de classes sociais. Assim, significa obter entendimentos diferentes para contextos históricos diferentes, obter novas estratégias de luta também para novas demandas. Como nos sugere Konder, Marx não poderia prever toda a força, nem toda a competência com que a burguesia defendeu sua hegemonia (ibid., p. 88), nem para os anos posteriores à sua morte - Em 1848, o campo de batalha era um; em 1895 havia-se modificado, era outro (ibid. p. 82) -, mais ainda se considerarmos tudo que aconteceria no século $X X$.

A questão ambiental é um dos elementos de uma nova pauta e ainda que não chegue a constituir uma $2^{\underline{a}}$ contradição (cf. CHESNAIS; SERFATI) imprime sobre "os vermelhos" importantes desafios teórico-práticos. Não nos parece que a luta dos trabalhadores possa desconsiderar a questão ambiental; de que a crença no desenvolvimentismo (por vezes também encontrado em Marx) não possa ser relativizada; de que em sua luta por sobrevivência, os menos abastados também não possam e já não estejam oferecendo novas respostas à degradação ambiental...

A destruição do planeta pode não ser uma contradição para o Sistema Capital, mas é para os homens...

\section{REFERÊNCIAS}

BOMFIM, Alexandre Maia. Desvendando a área de trabalho e educação: estudo sobre a produção e os produtores do GT Trabalho e Educação da Anped. Orientadora: Alicia Maria Catalano Bonamino. Rio de Janeiro: PUC, Departamento de Educação, 2006

BOTTOMORE, Tom (org.) Dicionário do Pensamento Marxista. Rio de Janeiro: Jorge Zahar, 2001.

CHESNAIS, François; SERFATI, Claude. "Ecologia" e condições físicas de reprodução social: alguns fios condutores marxistas. Crítica Marxista. São Paulo, n.16, Editora Boitempo, 2003. 
DELUIZ, Neise; NOVICKI, Victor. Trabalho, meio ambiente e desenvolvimento sustentável: implicações para uma proposta de formação crítica. Boletim Técnico do SENAC, 30(2) maio/ago, p. 18-29, 2004.

FRIGOTTO, Gaudêncio (org.). Educação e Crise do Trabalho. Petrópolis-RJ: Vozes, 1998.

IPCC - Painel Intergovernamental sobre Mudança do Clima (Intergovernmental Panel on Climate Change). Climate Change 2007. [Paris, 02 de fev. de 2007] Disponível em:<http://www.ipcc.ch>. Acesso em: 28 fev. 2007.

KONDER, Leandro. A Questão da Ideologia. São Paulo: CIA da Letras, 2002. .Filosofia e Educação: de Sócrates a Habermas. Rio de Janeiro: Forma \& Ação, 2006.

- Marx e a Sociologia da Educação. In TURA, Maria de Lourdes. Sociologia para educadores. Rio de Janeiro: Quartet, 2001.

. O Futuro da Filosofia da Praxis: o pensamento do marxismo no século XXI. Rio de Janeiro: Paz e Terra, 1992.

KOSIK, Karel. Dialética do Concreto. Rio de Janeiro: Paz e Terra, 1995.

.Dialética do Concreto.4 ed. Rio de Janeiro: Paz e Terra, 1986.

LOUREIRO, C. F. (org.) A Questão Ambiental no Pensamento Crítico: Natureza, Trabalho e Educação. Rio de Janeiro: Quartet, 2007.

LÖWY, M. Ecologia e Socialismo. São Paulo: Cortez, 2005.

LUXEMBURGO, Rosa. Reforma Social ou Revolução? 2 ed. SP: Global Editora, 1990.

MARX, Karl \& ENGELS, Frederic. A Ideologia Alemã. São Paulo: Editorial Grijalbo, 1977.

.Manifesto do Partido Comunista. São Paulo: Editora Escriba, 1968.

MÉSZÁROS, István. Para além do capital. Campinas: Boitempo, 2002.

OFFE, Claus. Trabalho a categoria chave da sociologia? Revista Brasileira de Ciências Sociais, Rio de Janeiro, ANPOCS n.10, jun. 1989. 
RODRIGUES, Alberto Tosi. Sociologia da Educação. Rio de Janeiro: DP\&A, 2003.

i Doutor em Educação Brasileira pela PUC-Rio; professor do Programa de Pósgraduação Stricto Sensu em Ensino de Ciências (Propec) do Instituto Federal de Educação, Ciência e Tecnologia do Rio de Janeiro. E-mail: alexmab@uol.com.br

ENVIADO EM 13.04.2011

APROVADO EM: 30.06.2011 